\title{
Effect of Moringa Oleifera Leaf Extract on Oxidative Stress and Theca Cell in Polycystic Ovary Syndrome Model with Insulin Resistance
}

\author{
Lisa Purbawaning Wulandari ${ }^{1}$, Budi Santoso ${ }^{2}$, Bambang Purwanto ${ }^{3}$, \\ Muhammad Miftahussurur ${ }^{4}$, Jimmy Yanuar Annas ${ }^{5}$, Budiono $^{6}$ \\ ${ }^{1}$ Researcher of School of Reproduction Health, Faculty of Medicine, Universitas Airlangga, Surabaya, Indonesia, \\ ${ }^{2}$ Lecturer of Fertility and Reproductive Endocrinology Division, Department of Obstetrics and Gynecology, \\ Faculty of Medicine-Dr. Soetomo Teaching Hospital, Universitas Airlangga, Surabaya, Indonesia, 3 Lecturer \\ of Department of Physiology, Faculty of Medicine, Universitas Airlangga, Surabaya, Indonesia, ${ }^{4}$ Lecturer of \\ Gastroentero-Hepatology Division, Department of Internal Medicine, Faculty of Medicine-Dr. Soetomo Teaching \\ Hospital-Institute of Tropical Disease, Universitas Airlangga, Surabaya, Indonesia, ${ }^{5}$ Lecturer of Department of \\ Obstetrics and Gynecology, Faculty of Medicine-Dr. Soetomo Teaching Hospital, Universitas Airlangga, Surabaya, \\ Indonesia, ${ }^{6}$ Lecturer of Department of Epidemiology, Faculty of Medicine, Universitas Airlangga, Surabaya,
} Indonesia

\begin{abstract}
Background: The use of Moringa oleifera as an antioxidant should be investigated as an alternative treatment of oxidative stress and follicular refinement in PCOS with insulin resistance.

Purpose: We aimed to prove the effect of Moringa oleifera leaf extract in various dosages to decrease the malondialdehyde levels and theca cell thickness of PCOS female rat with insulin resistance.

Method: Three month old Rattus norvegicus stran wistar rat weighing 100-130 grams were divided into 5 groups $(\mathrm{n}=8)$. PCOS model obtained by giving injection of testosterone propionate for 28 days, followed by metformin therapy and Moringa oleifera leaf extract at 250 and $500 \mathrm{mg} / \mathrm{KgBW}$ for 14 days. Then, we analyzed levels of malondialdehyde in the blood and the thickness of theca cell.

Results: Malondialdehyde levels in the PCOS control group (5.694 \pm 1.464$)$ increased significantly $(\mathrm{p}<0.05)$ compared to the normal controls (1.939 \pm 0.341$)$. Leaf extract Moringa oleifera $500 \mathrm{mg} / \mathrm{KgBW}(1.982 \pm 0.383)$ showed a significant decrease $(\mathrm{p}<0.05)$ to malondialdehyde levels compared to the PCOS control group. Examination of ovarium histology showed that leaf extract Moringa oleifera $500 \mathrm{mg} / \mathrm{KgBW}(0.931 \pm 0.457)$ significantly decreased the thickness of theca cells $(p<0.05)$ compared to the PCOS control group.

Conclusion: Moringa oleifera leaf extract as an antioxidant proven to decrease the malondialdehyde levels and the thickness of theca cell of the female rat model of PCOS.
\end{abstract}

Keywords: Moringa oleifera, Polycystic Ovary Syndrome, malondialdehyde, Theca Cell Thickness.

\section{Corresponding Author:}

Prof. Dr. H. Budi Santoso Dr, SpOG(K)

Lecturer of Fertility and Reproductive Endocrinology Division, Department of Obstetrics and Gynecology, Faculty of Medicine-Dr. Soetomo Teaching Hospital, Universitas Airlangga, Surabaya, Indonesia e-mail: budi.santoso (at) fk.unair.ac.id

\section{Introduction}

Polycystic Ovary Syndrome (PCOS) was the most common endocrinopathy in women, thus the affects 5 to $10 \%$ of women of reproductive age, $50-70 \%$ have insulin resistance, $35 \%$ of endometrial hyperplasia, 5-3 times could occur endometrial cancer, 36-56 \% experienced recurrent pregnancy loss ${ }^{(1)}$. The prevalence of clinical presentation of PCOS varies were considerably. ${ }^{(2)}$. 
The definition of PCOS includes both clinical and biochemical criteria as well as ovarium morphology ${ }^{(3)}$. PCOS have been regarded as a chronic systemic disease rather than a simple local disease, and it was often associated with insulin resistance, hyperandrogenemia, chronic inflammation, and oxidative stress, although pathogenesis has not been well defined. (4). Insulin and IGF-1 indirectly also could increase androgen levels by decreasing the production of SHBG (Sex Hormone Binding Globulin) in the liver and suppress the synthesis of IGFBP-1 (Insulin-Like Growth Factor Binding Protein-1) directly, quickly, and completely liver and ovaries so that levels of IGF-I, IGF-II, and free testosterone were increased ${ }^{(5)}$

Moreover, in previous research it has revealed that OS levels were significantly increased in patients with PCOS compared with normal, when oxidative status was evaluated by circulating markers, such as malondialdehyde (MDA), superoxide dismutase (SOD), and glutathione peroxidase (GPx) ${ }^{(6)}$.. Research conducted by Sabuncu et al (2001), Zhang et al (2008) and Kuscu et al (2009) showed significantly elevated levels of serum MDA levels in PCOS patients compared with non-PCOS ${ }^{(7)}$

Metformin is the first line of PCOS obese treatment by inhibiting hepatic glucose absorption, increasing peripheral glucose uptake, reducing peripheral insulin levels, and improving GLUT-4 ${ }^{(8)}$. Metformin treatment might not be suitable for a long-term PCOS treatment.

The search for herbs that have potential capabilities as preventative and scientifically proven could be used for treatment alternative a much-needed. Phytochemical studies of the Moringa oleifera plant that revealed large polyphenols such as quercetin glucoside, routine, kaempferol glycoside, and chlorogenic acid in Moringa oleifera flour via HPLC analysis ${ }^{(9)}$. Quercetin exhibits activity as an antioxidant by decreasing lipid peroxidation (MDA) and increasing antioxidant enzyme activity in STZ-induced diabetic-induced mouse mellitus ${ }^{(10) .}$

In this study, we aimed to determine that giving Moringa oleifera leaf extract as an antioxidant could decrease the MDA levels and follicle repair in PCOS with insulin resistance. This plant was an original plant in various Asian countries, abundant and cheap as a food source. Thus, every health benefit of this plant will reach most of the population.

\section{Method}

Moringa oleifera commonly referred as the miracle tree that was a family of Moringaceas originating from southern Asia. The leaves of this tree are rich in minerals, vitamins and other important phytochemicals (11). Moringa oleifera extract (Kelorina, Moringa Indonesia, Blora, Indonesia) in powder form, all the process was done according to standard to obtain Moringa oleifera extract. The Moringa oleifera leaf was also used in several studies to determine its effectiveness in chronic hyperglycemia and dyslipidemia ${ }^{(12)}$.

The female rat of Rattus norvegicus strain Wistar (Biochemistry Laboratory, Faculty of Medicine, Airlangga University, Surabaya, Indonesia) was 3 months old and weighed 100-130 grams. These rat were also used in research as animal models of diabetes ${ }^{(13)}$. Before the study began, it gives the period of adaptation for a week, in healthy condition, in normal behaviour and the results of normal vaginal swab. We excluded rat with anatomical abnormalities and in pregnant during the adaptation. All procedures described were approved by the ethics committee of the Faculty of Veterinary Medicine of Universitas Airlangga.

The white wistar strain female rats (Rattus norvegicus) of 40 samples were divided into 5 groups randomly $(\mathrm{n}=8)$. Normal control group was only given aquades, while the other four groups were PCOS model. Preparation of PCOS with insulin resistance model using testosterone propionate injection (Testohormon, Wonderindo Pharmatama, Jakarta, Indonesia), this hormone was given intramuscularly in the thigh with a dose of $1 \mathrm{mg} / 100 \mathrm{grBW}$ once a day for 28 days until PCOSresistance insulin model obtained. Furthermore, the second group as the positive control only given aquades, then the third group was followed by giving metformin therapy $(2 \mathrm{mg} / 100 \mathrm{gBW}$, orally) as the comparison while the fourth and fifth group followed by giving Moringa extract oleifera orally $(250 \mathrm{mg} / \mathrm{KgBW})$ and $(500 \mathrm{mg} /$ $\mathrm{KgBW}$ ) for 14 days. Before and after the study period, animals try to swab the vagina to know what cycle was ongoing before and after the study. Before the animal was sacrificed, it has fasted for 12 hours and then blood was taken to analyze MDA levels and ovarium removal to measure the thickness of the theca cell.

The measurements of MDA levels using blood serum specimens of rat were examined using the thiobarbituric acid (TBA) reagents by reaction with a nucleophilic 
addition that forming the MDA-TBA compound. Then measured its intensity by using a spectrophotometer at $532 \mu \mathrm{m}$ wavelength with the simple spectrophotometric method was done in Biochemistry Laboratory, Faculty of Medicine, Universitas Airlangga, Surabaya, Indonesia.

The thickness of theca cells follicle was examined by HE staining (Hematoxylin-Eosin). Later on, HE was a colouring method widely used in tissue staining, aiming to make it easier to see changes in the tissue. The preparation of ovarium organs was coloured with a hematoxylin-eosin dye, so it could be clearly seen the shape of each cell. The coloured tissue was then placed on the glass object (object glass) which was covered with a glass cover (cover glass) that has been previously spilled with entellan, then the tissue was observed under a microscope.
Normality test using Shapiro-wilk test. All results were statistically analyzed using SPSS statistical software package version 18.0 (SPSS, Inc., Chicago, IL). One-way factorial analysis of ANOVA variance or Krukal Wallis test were performed based on the distribution data. The data were considered statistically significant at value $\mathrm{p}<0.05$.

\section{Results}

The results of the vaginal swab after treatment showed that there was a diestrus phase in the group receiving 1 $\mathrm{mg} / 100 \mathrm{grBW}$ injection treatment intramuscular for 28 days (Table 1).

Table 1. Distribution of the weight, frequency (grams) of female rat models of PCOS before and after treatment

\begin{tabular}{|l|c|c|c|c|c|}
\hline \multirow{2}{*}{ Samples } & \multicolumn{5}{|c|}{ Groups } \\
\cline { 2 - 6 } & K1 & K2 & K3 & K4 & K5 \\
\hline Mean Before & 115.50 & 121.88 & 118.62 & 112.75 & 119.12 \\
\hline Mean After & 174.25 & 195.88 & 195.62 & 179.00 & 174.75 \\
\hline Mean Increases & 58.75 & 74 & 77 & 66.25 & 55.63 \\
\hline
\end{tabular}

$\mathrm{K} 1$ : normal control group; K2: PCOS insulin resistance control group; K3: PCOS insulin resistance metformin group; K4: PCOS insulin resistance Moringa oleifera leaf extract $250 \mathrm{mg} / \mathrm{KgBW}$ group; K5: PCOS insulin resistance Moringa oleifera leaf extract 500mg/ KgBW group.

The results of MDA level measurements on blood samples of female rats (Table 2) showed that significant oxidative stress increased in the PCOS- insulin resistance control group compared to the normal control group ( $\mathrm{p}$ $<0.05$ ). The Moringa oleifera leaf extract group showed the significantly decreased of MDA levels in female PCOS-insulin-resistance $(\mathrm{p}<0.05)$. The group given Moringa oleifera leaf extract at $500 \mathrm{mg} / \mathrm{KgBW}$ resulted lowest MDA levels compared to the PCOS-insulin resistance control group $(\mathrm{p}<0.05)$ (Table 2$)$.

Table 2. Effect of treatment on serum MDA parameters

\begin{tabular}{|l|c|c|c|c|c|}
\hline \multirow{2}{*}{ Samples } & \multicolumn{5}{|c|}{ Groups } \\
\cline { 2 - 6 } & K1 & K2 & K3 & K4 & K5 \\
\hline Quantity of MDA & $1.939 \pm 0.341$ & $5.694 \pm 1.464^{*}$ & $3.759 \pm 1.384$ & $3.315 \pm 1.128^{* *}$ & $1.982 \pm 0.383^{* *}$ \\
\hline
\end{tabular}

*significantly different from normal control $(\mathrm{p}<0.05) * *$ significantly different from PCOS control-insulin resistance $(\mathrm{p}<0.05)$

K1: normal control group; K2: PCOS insulin resistance control group; K3: PCOS insulin resistance metformin group; K4: PCOS insulin resistance Moringa oleifera leaf extract $250 \mathrm{mg} / \mathrm{KgBW}$ group; K5: PCOS insulin resistance Moringa oleifera leaf extract $500 \mathrm{mg} /$ $\mathrm{KgBW}$ group. 
The results of measurements of theca cell thickness on ovary samples of control female rats and treated groups using the HE method showed that the PCOS control group had higher cell-density cells than the other groups. The group treated with the leaf extract of Moringa oleifera at the dose of $500 \mathrm{mg} / \mathrm{KgBW}$ had a lower theca cell thickness than the other group. Metformin and Moringa oleifera leaf extracts showed the significant decrease in the thickness of theca cell $(\mathrm{p}$ $<0.05)$ compared to the PCOS-insulin resistance control group (Table 3).

Tabel 3. Effect of treatment on histological parameters

\begin{tabular}{|l|c|c|c|c|c|}
\hline \multirow{2}{*}{ Sampel } & \multicolumn{5}{|c|}{ Kelompok } \\
\cline { 2 - 7 } & K1 & K2 & K3 & K4 & K5 \\
\hline Ketebalan sel teka & $1.573 \pm 0.551$ & $0.000 \pm .000^{*}$ & $1.950 \pm 0.577^{* *}$ & $2.187 \pm 0.860^{* *}$ & $0.931 \pm 0.457 * *$ \\
\hline
\end{tabular}

*significantly different from normal control $(\mathrm{p}<0.05) * *$ significantly different from PCOS control-insulin resistance $(\mathrm{p}<0.05)$

K1: normal control group; K2: PCOS insulin resistance control group; K3: PCOS insulin resistance metformin group; K4: PCOS insulin resistance Moringa oleifera leaf extract $250 \mathrm{mg} / \mathrm{KgBW}$ group; K5: PCOS insulin resistance Moringa oleifera leaf extract $500 \mathrm{mg} /$ $\mathrm{KgBW}$ group.

\section{Discussion}

The PCOS model in this study shows that oxidative stress has occurred. There was a significant difference between the normal and the PCOS control group, it was indicating that the successful of PCOS modelling was characterized by significant increases in MDA levels. Testosterone, an androgens causes an increase in oxidative stress by facilitating lipolysis and the breakdown of abdominal fat leading to increased free fatty acids ${ }^{(14)}$. The statistical results showed a significant difference between PCOS control group and Moringa oleifera group, whereas between PCOS control group and metformin group showed no significant difference.

Moreover, the Moringa oleifera leaf extract in a female mouse model of PCOS as antioxidant in this research was proven to decrease the MDA level. MDA levels of the group given Moringa oleifera leaf extract at doses of $500 \mathrm{mg} / \mathrm{KgBW}$ had a better decrease than the metformin group and the Moringa oleifera group at $250 \mathrm{mg} / \mathrm{KgBW}$, this result was close to normal control. Moringa oleifera leaf extract in Wistar strain rats might protect it from oxidative stress with decreased MDA levels compared with normal diet ${ }^{(15) \text {. }}$

The PCOS model in this study increased the thickness of the theca cell. The PCOS control group significantly increased the thickness of the theca cells compared with the normal control group. Women with PCOS syndrome usually have an enlarged ovary with an increased number of follicles and volume of the stroma. The treatment of high-dose androgens causes suppression of gonadotropin, but their ovaries were not depressed but enlarged by the increasing number of "cystic" follicles and theca-interstitial hyperplasia, meeting the PCOS morphology criteria. These observations show that androgens could cause growth of ovarian and thecainterstitial follicles $\left.{ }^{(16}\right)$. The previous studies whose using rat that was given testosterone injections for 28 days also showed a change in ovarian morphology including the presence of thickening of theca cells ${ }^{(17) .}$

Furthermore, the drumstick tree was a rich plant in nutrients as well as macro, micronutrients, minerals, and vitamins. The nutrient content of the powder of the drumstick tree leaf was Vitamin A 16,3 $\mathrm{mg} / 100 \mathrm{gr}$, vitamin C $17,3 \mathrm{mg} / 100 \mathrm{gr}$, vitamin E 113,6 $\mathrm{mg} / 100 \mathrm{gr}$, flavonoid $473,3 \mathrm{mg} / \mathrm{gr}$ also selenium 0,9 $\mu \mathrm{g} / 100 \mathrm{gr}$. Vitamin E was the most important fat-soluble antioxidant and protects against lipid membranes from oxidative damage. Vitamin $\mathrm{E}$ has a major function as a fat-soluble antioxidant and it was easy to provide hydrogen from the hydroxyl $(\mathrm{OH})$ groups in the ring structure to free radicals. Vitamin $\mathrm{E}$ improves the potential for free radical defene systems and has a beneficial effect in the improvement of glucose transport and insulin sensitivity. Previous research conducted by Rzepczynska et al (2011) proves that administration of anti-oxidants (vitamin E) could improve the theca cell in rats induced by $17 \beta$ estradiol ${ }^{(18)}$. Study of antioxidant effects (routine flavonoids) in PCOS showed that there was an improvement in theca cell and oxidative stress cells in letrozole-induced rat ${ }^{(19)}$. 
Other studies have shown that Moringa oleifera can reduce blood insulin levels, then decrease androgens thereby allowing an increase in folliculogenesis in $\operatorname{PCOS}^{(20)}$. On the other hand, insulin is related to other aspects of reproduction. Insulin Transferrin Selenium and Bovine Serum Albumincan increase the amount of fertilization and support the development of embryos $^{(21)}$. Sperm quality including motility, viability and membrane integrity are lower after centrifugation for sperm viability, motility, membrane integrity and capacitation $^{(22) \text {. }}$

\section{Conclusion}

This study showed that the extract of Moringa oleifera leaf as an antioxidant could decrease the MDA levels and cell follicular thickness of PCOS rats along with insulin resistance induced by testosterone propionate.

Ethical Clearance: This study received an ethical test from Dr. Soetomo General Hospital and faculty of medicine Universitas Airlangga.

Source of Funding: This research was carried out through individual funding.

Conflict of Interest: There was no conflict of interest from this study.

\section{References}

1. Homburg R. Polycystic ovary syndrome. Best Practice \& Research Clinical Obstetrics \& Gynaecology. 2008;22(2):261-74.

2. Balen AH, Conway GS, Homburg R, Legro RS. Polycystic ovary syndrome: a guide to clinical management: CRC Press; 2005.

3. Fauser BC, Tarlatzis BC, Rebar RW, Legro RS, Balen AH, Lobo R, et al. Consensus on women's health aspects of polycystic ovary syndrome (PCOS): the Amsterdam ESHRE/ASRMSponsored 3rd PCOS Consensus Workshop Group. Fertility and sterility. 2012;97(1):28-38. e25.

4. Touyz RM. Molecular and cellular mechanisms in vascular injury in hypertension: role of angiotensin II-editorial review. Current opinion in nephrology and hypertension. 2005;14(2):125-31.

5. Rojas J, Chávez M, Olivar L, Rojas M, Morillo $\mathrm{J}$, Mejías J, et al. Polycystic ovary syndrome, insulin resistance, and obesity: navigating the pathophysiologic labyrinth. International journal of reproductive medicine. 2014;2014.

6. Zuo T, Zhu M, Xu W. Roles of oxidative stress in polycystic ovary syndrome and cancers. Oxidative medicine and cellular longevity. 2015;2016.

7. Yeon Lee J, Baw C-K, Gupta S, Aziz N, Agarwal A. Role of oxidative stress in polycystic ovary syndrome. Current Women's Health Reviews. 2010;6(2):96-107.

8. Huang Y, Sun J, Wang X, Tao X, Wang H, Tan W. Asymptomatic chronic gastritis decreases metformin tolerance in patients with type 2 diabetes. Journal of clinical pharmacy and therapeutics. 2015;40(4):461-5.

9. Johnson B. Clinical perspectives on the health effects of Moringa oleifera: A promising adjunct for balanced nutrition and better health. KOS health publications; 2005.

10. Adewole SO, Caxton-Martins EA, Ojewole JA. Protective effect of quercetin on the morphology of pancreatic $\beta$-cells of streptozotocin-treated diabetic rats. African Journal of Traditional, Complementary and Alternative Medicines. 2007;4(1):64-74.

11. Sujatha B, Patel P. Moringa Oleifera-Nature's Gold. Imperial Journal of Interdisciplinary Research. 2017;3(5).

12. Mbikay M. Therapeutic potential of Moringa oleifera leaves in chronic hyperglycemia and dyslipidemia: a review. Frontiers in pharmacology. 2012;3.

13. Purwanto B, Sudiana IK, Herawati L, Aksono B. MUSCLE GLUCOSE TRANSPORTER 1 (GLUT1) EXPRESSION IN DIABETIC RAT MODELS. Folia Medica Indonesiana. 2013;49(1):21-5.

14. Marshall K. Polycystic ovary syndrome: clinical considerations. Alternative Medicine Review. 2001;6(3):272-

15. Oparinde DP, Atiba AS. Moringa oleifera Leaf Prevents Oxidative Stress in Wistar Rats. 2014.

16. Vendola KA, Zhou J, Adesanya OO, Weil SJ, Bondy CA. Androgens stimulate early stages of follicular growth in the primate ovary. Journal of Clinical Investigation. 1998;101(12):2622.

17. Wu C, Lin F, Qiu S, Jiang Z. The characterization of obese polycystic ovary syndrome rat model suitable for exercise intervention. PloS one. 2014;9(6):e99155. 
18. Rzepczynska IJ, Foyouzi N, Piotrowski PC, CelikOzenci C, Cress A, Duleba AJ. Antioxidants induce apoptosis of rat ovarian theca-interstitial cells. Biology of reproduction. 2011;84(1):162-6.

19. Jahan S, Munir F, Razak S, Mehboob A, Ain QU, Ullah $\mathrm{H}$, et al. Ameliorative effects of rutin against metabolic, biochemical and hormonal disturbances in polycystic ovary syndrome in rats. Journal of ovarian research. 2016;9(1):86.

20. Amelia,D.,Santoso,B.,Purwanto,B.,Miftahussurur, M., Joewono, H.T.,Budiono. Effects of Moringa oleifera on insulin levels and folliculogenesis in polycystic ovary syndrome model with insulin resistance. Immunology, Endocrine and Metabolic Agents in Medicinal Chemistry . 2018; 18(1):22-30
21. Widjiati,Luqman, E.M., Tehupuring, B.C. Effectivity of Insulin Transferrin Selenium and Bovine Serum Albumin addition on in vitro culture medium on fertilization and blastocyst rate of mice (Mus musculus). Journal of International Dental and Medical Research. 2017; 10(3):1080-1083

22. Susilowati, S.,Triana, I.N.,Malik, A. The effects of insulin-like growth factor I (IGF-I) complex from seminal plasma on capacitation, membrane integrity and DNA fragmentation in goat spermatozoa(Article)(Open Access) . Asian Pacific Journal of Reproduction. 2015; 4(3): 208-211 